\title{
Exploring the Self-efficacy Beliefs among the High Achievers in Writing
}

\author{
Ilyana Jalaluddin (Corresponding author) \\ English Department, Faculty of Modern Languages and Communication \\ Universiti Putra Malaysia, 43400 Serdang, Malaysia \\ Tel: +60389468938 E-mail: ilyana@upm.edu.my
}

Received: 10-09-2013

doi:10.7575/aiac.ijalel.v.3n.1p.100
Accepted: 22-10-2013

Published: 01-01-2014

URL: http://dx.doi.org/10.7575/aiac.ijalel.v.3n.1p.100

\begin{abstract}
Learners form their self-efficacy beliefs by interpreting information primarily from four sources namely performance accomplishments, vicarious experiences, verbal persuasion, and emotional arousal. It is important to recognize the four cognitive nature of self-efficacy because the cognitive appraisal of information from the four sources will influence self-efficacy and it cannot be evaluated based on one source per se (Lane, Jones \& Stevens 2002). This article explores the four sources of self-efficacy among the high achievers in writing course. In analysing the finding, Z-scores were derived from each self-efficacy component score based on the aggregate mean and the standard deviation of the class. Findings show high frequency of negative z-value reported for Specific Progress (SPR) and Social Feedback (SF). Meanwhile, high frequency of positive z-value is found in the General Progress (GPR) and Physiological States (PS) components. Based on the finding, pedagogical implications, limitations and directions for further research are presented.
\end{abstract}

Keywords: writing self-efficacy, writing skills, L2 high achiever writers

\section{Introduction}

Socio-cognitive framework posited that all the aspects of engagement as well as learning and achievement are related to self-efficacy. This means thatself-efficacy can lead to more engagement to proceed with the writing tasks and, subsequently, to more learning and better achievement in writing. However, the relations also flow back to self-efficacy over time. Accordingly, the more learners are engaged, and especially the more they learn and the better they perform, the higher their self-efficacy. Conversely, the more the learners feel confused with the topic and less assistance received from environmental factors, the lower their self-efficacy will be. Hence, the arrow for motivational engagement flow back to self-efficacy from learning and achievement. This can be represented by Figure 1 below;

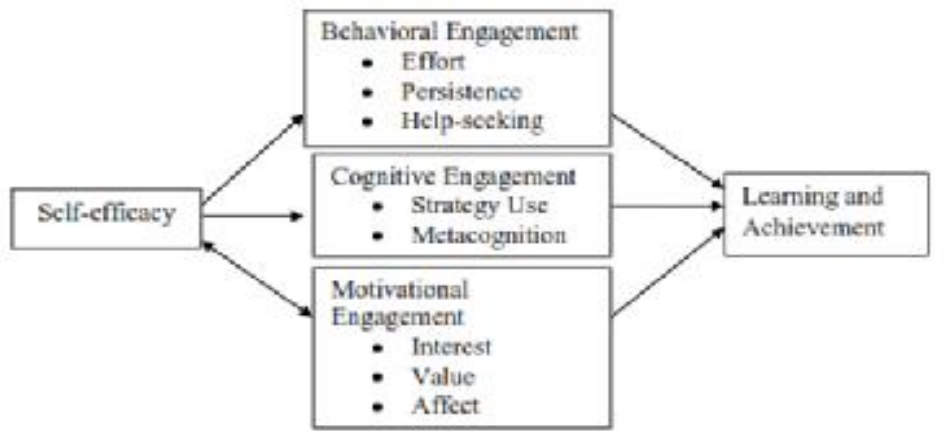

Figure 1. A general framework for self-efficacy, engagement, and learning.

Perceived self-efficacy thus occupies an essential role in the causal structure of Social Cognitive Theory because selfefficacy beliefs affect adaptation and change not only in their own right, but through their impact on other determinants (Bandura 1997). According to Pajares and Valiante (2008), the self-efficacy that the learners come to hold about their capabilities in their writing skills will influence the choices they make and the course of action they pursue. This shows that learners actually select writing tasks and activities in which they feel competent and confident to carry out, and they will avoid those in which they do not feel confident at all. Unless they believe that their actions will have the desired consequences, they will have little incentives to engage in those actions (Pajares \& Valiante 2008). This implies that writing efficacy beliefs play a key role in shaping the course of lives taken, by influencing the types of activities and environments learners choose to get into. 
Furthermore, self-efficacy beliefs help to determine "how much effort learners will expend on an activity, how long they will persevere when confronting obstacles, and how resilient they will be in the face of adversity" (Pajares \& Valiante 2008:159). Here, efficacy beliefs play a central role in the self-regulation of motivation through goal challenges and outcome expectations. It is partly on the basis of efficacy beliefs that learners choose what challenges to undertake, how much effort to expend in the attempt, and how long to persevere in the face of obstacles and failures. Thus, learners with a strong sense of personal competence in a writing task will most probably approach difficult tasks as a challenge to be mastered rather than as threats to be avoided. According to Pajares and Valiante (2008:159), "learners with high self-efficacy have greater intrinsic interest and deep engrossment in activities, set themselves challenging goals and maintain strong commitment to them, and heighten and sustain their efforts in the face of failures". Moreover, they are more quickly to recover their sense of efficacy after failures or setbacks, and attribute failures to effort or deficient knowledge and skills that are acquirable (Bandura 1997).

Finally, self-efficacy beliefs also influence thought patterns and emotional reactions (Pajares \& Valiante 2008). Thus, learners with low writing self-efficacy may believe that writing is tougher than it really is and thus fosters anxiety, stress, and a narrow vision of how best to solve a problem. According to Schunk (2003), learners who do not feel confident about their writing, may not feel the corresponding positive feeling of self-worth because they take no pride in their writing accomplishment. Obviously, such affective reactions can powerfully influence the level of accomplishment that one finally achieves. This function of self-efficacy can also create the type of self-fulfilling prophecy in which a learner may accomplish what he or she believes can be accomplished, that is, the perseverance associated with high self-efficacy which is likely to lead to increased performance that in turn raises his or her sense of efficacy and spirit (Pajares 1995; 2002).

In sum, based on the discussion above, it shows that writing efficacy influences learners' behaviour in three ways. First, they influence choice of behaviour. Learners engage in tasks in which they feel competent and confident, and avoid those in which they do not. Secondly, they help determine how much effort a learner will expend on an activity and how long a learner will persevere. The higher the sense of writing efficacy, the greater the effort expenditure and persistence are in the writing process. Finally, writing self-efficacy beliefs influence learners' thought patterns and emotional reactions. Learners with low self-efficacy may believe that writing is tough task, a belief that fosters stress and a narrow vision of how to solve a problem. High self-efficacy, on the other hand, creates feelings of serenity in approaching difficult tasks (Pajares 1995).

Given the significant influence of self-efficacy has on learning, it is thus very important to develop and maintain one's self-efficacy in writing. Nevertheless, according to Klassen (2002), in almost all of the studies that included direct comparisons of levels of efficacy beliefs, whether the studies compared pairs of cultural groups (e.g. Pastorelli et al, 2001) or a large number of cultural groups (e.g. Scholz et al, 2002), self-efficacy beliefs were typically higher for participants from Western than for the participants from Asian. Thus, it is important to investigate self-efficacy beliefs in a Malaysian setting where the culture and learning environment are different. This paper will specifically focus on the high achievers group in a writing course and examines the four hypothesized self-efficacy sources in detailed. In comparison to previous research, the present study quantitatively examined each component of self-efficacy to describe the thought and belief of skilled writers in a writing course rather look at it as an overall level of self-efficacy. It is hoped that by looking at these high-achiever, the question of 'what motivates them to be a high achiever in writing' can be explained.

\section{Purpose of the study}

The study aims to investigate writing self-efficacy characteristics in writing among tertiary learners and specifically, the discussion of the article focuses on these two research questions;

1. What is Universiti Putra Malaysia(UPM) learners' writing self-efficacy level?

2. What are the implications that writing self-efficacy has on teaching and learning of writing skills?

\section{Literature Review}

There are four sources that need to be considered when evaluating self-efficacy. Learners form their self-efficacy beliefs by interpreting information primarily from four sources: 1) performance accomplishments, 2) vicarious experiences, 3) verbal persuasion, and 4) emotional arousal. Thus, these four sources will be discussed in detail by relating them closely to writing in the next sections.

\subsection{Enactive mastery experiences (performances)}

Of these four information sources, research has shown that enactive mastery experiences are the most influential source of efficacy information because they provide the most direct, authentic evidence that an individual can gather the personal resources necessary to succeed (Bandura 1997). As one might expect, past successes raise efficacy beliefs, while repeated failures, in general, lower them (Bandura, 1977). This can be applied in writing context where leaners who experience success in the writing tests or examinations in the past, mayhave higher self-efficacy beliefs in writing. However, when repeated failures occurred in the writing tasks, the learners may see writing as difficult task and have low self-efficacy beliefs to engage in the writing activities. However, the influence of performance successes and failures is a bit more complex than this. For example, "after strong efficacy expectations are developed through repeated success, the negative impact of occasional failures is likely to be reduced" (Artino 2006:3). Thus, the effects of previous failures in writing on personal efficacy really also depend on the strength of individuals' existing efficacy beliefs, as 
well as the timing of failures with respect to the totality of their performance experiences. In other words, later failures may not negatively impact writing efficacy beliefs to the same extent as earlier failures might if the writer manages to heal back or improve their self-efficacy. Methods used to develop performance accomplishments include teacher's modelling of writing process, performance desensitisation, and performance exposure by the teacher (Strauser 1995).

\subsection{Observation of others (vicarious experiences)}

While experienced mastery has been shown to produce the most powerful influence on efficacy beliefs, individuals can also learn by observing the successes and failures of others. Pajares (2002) described vicarious experiences as a significant model in one's life which can help instill self-beliefs that will influence the course and direction that life will take. This means that by observing successful performances, the individual comes to believe that he or she can also perform the writing task effectively. "Bandura asserted people who have been observed would normally be treated as model, and the learning process through the observation of the model's behaviours known as modelling" (Mok Soon Sang 2008:80). For example, learners are likely to develop the belief that 'I can do that' when a highly regarded teacher models excellence in an academic endeavour or writing activities. Bandura's (1997) process of observation can be depicted in Figure 2 below;

$$
\begin{aligned}
\text { Pupil A }- \text { Observes } \rightarrow & \begin{array}{l}
\text { Pupil B } \\
\text { recites } \\
\text { writes } \\
\text { story }
\end{array}
\end{aligned} \text { Peinforcement: } \rightarrow \begin{aligned}
& \text { Imitation: } \\
& \text { Praise from teacher }
\end{aligned} \quad \begin{aligned}
& \text { Tendency of pupil A to } \\
& \text { write story strengthened }
\end{aligned}
$$

Figure 2. Process of observation learning (Modelling)

According to Bandura $(1977,1997)$, vicarious experiences can generate efficacy beliefs in observers that they too can attain success through persistence and effort. Efficacy is also increased when an individual observes a variety of models achieving success, instead of just one model (Strauser, 1995).

\subsection{Social persuasion}

A third source of efficacy information comes from verbal persuasion or social message that people receive from others. Similar to vicarious experiences, verbal persuasion also perhaps has less influence on writing self-efficacy compared to performance accomplishments (enactive mastery experience). Such social persuasion nevertheless is widely used by teacher in the classroom to help learners believe that they can actually cope with difficult situations. As mentioned earlier, many Malaysian learners feel that writing is a difficult task. Therefore, social persuasion is important to boost their confidence in writing. According to Pajares (2002), learners can recall something that was said to them (or done to/for them) previously that had a profound effect on their confidence throughout the rest of their life. Successful social message from teachers will cultivate learners' beliefs in their capabilities, while at the same time ensuring that envisioned success is attainable (Pajares, 2002). However, self-efficacy is easily weakened if failures are experienced. Here, teachers play an important part in the development of an individual's self-beliefs (Pajares \& Valiante 2008). "Verbal suggestions by the teacher, exhortation, self-instruction, and interpretative treatments are strategies that may frequently be used in the classroom" (Strauser, 1995:8).

\subsection{Physiological states}

The fourth and final source of efficacy information comes from learners' own physiological and emotional feedback during performance, particularly those involving physical activities. For example, according to Bandura $(1977,1997)$, individuals interpret stress reactions (e.g. increased heart rate, sweating, hyperventilation, and feelings of anxiety and fear) during demanding tasks as signs of vulnerability. Similarly, when Malaysian learners look at writing as a demanding task and feel fear towards it, it can affect their performance. When learners experience aversive thoughts and fear about their capabilities, those negative affective reactions can themselves trigger the stress and agitation, and causing inadequate performance (Pajares 2002a, 2002b). For example, if anxiety is experienced in performing a writing task, that emotional arousal may be interpreted by the learner that he or she is not coping effectively. In order to decrease emotional arousal and increase efficacy expectations, the use of attribution, relaxation, feedback and symbolic exposure by the teacher are methods which can be used (Strauser, 1995).

\section{Method and data source}

\subsection{Participants and Procedures}

Participants were 33 final year undergraduate learners majoring in Applied Linguistics and Literature. There were 13 boys and 20 girls comprising of 6 Bachelor of Arts (Literature) and 27 Bachelor of Arts (English studies) students. Instruments were group administered in the individual classes. During the first class period, learners were asked to complete the writing self-efficacy (WSE) questionnaire. Directions and individual items were read aloud by the administrator. Throughout the course that was 14 weeks, the learners were asked to write five assignments and two evaluators were involved to assess and determine the level of writing skills. Based on the assignment scores and proficiency background, eight students were identified as high achievers in writing. These eight learners will be the focus of discussion in this paper. Their level of writing self-efficacy will be analysed whereby Z-score is utilized to allow the researcher compare the four different concepts of self-efficacy. 


\subsection{Instruments}

The aim of this study is to analyse in depth the writing self-efficacy level of the high achiever in writing and the implications that we may draw from this connection. Based on these aims, writing self-efficacy questionnaire was used for the purpose of the discussion.

\subsubsection{Writing self-efficacy}

This study used Writing Self-Efficacy (WSE) questionnaire to measure the learners' writing self-efficacy. The questionnaire was adapted from Writing Self-Efficacy Scale prepared by Bottomley, Henk and Melnick (1998). The questionnaire was administered during the first and final week of the research period. It consisted of 37 items that were based on the four scales proposed by Albert Bandura (1986) when measuring one's self-efficacy as displayed in Table 1 below. The four scales are General (GPR - Question 3, 6, 12, 14, 16, 17, 18, 19) and Specific Progress (SPR - Question 21, 24, 28, 30, 33, 35, 37), Observational Comparison (OC - Question 1, 4, 8, 11, 15, 20, 22, 25, 29), Social Feedback (SF - Question 5, 9, 10, 13, 27, 32, 36), and Physiological States (PS - Question 2, 7, 23, 26, 31, 34).

Table 1. Bandura's elements of self-efficacy in questionnaire

\begin{tabular}{ll}
\hline Items in Questionnaire & Bandura's elements of self-efficacy \\
\hline $\begin{array}{l}\text { General Progress (GPR) and Specific } \\
\text { Progress (SPR) }\end{array}$ & $\begin{array}{l}\text { Enactive mastery experiences } \\
\text { (performances) } \\
\text { Observational Comparison (OC) }\end{array}$ \\
$\begin{array}{l}\text { Observation of others (vicarious } \\
\text { experiences) }\end{array}$ \\
Social Feedback (SF) & $\begin{array}{l}\text { Social persuasion } \\
\text { Physiological States (PS) }\end{array}$ \\
\hline
\end{tabular}

\subsubsection{Writing tasks}

During the course, learners were asked to produce a 3-4 pages essay for each written assignment. The written assignment ranged from argumentative essay discussing about the speech delivered by important people by looking at how effective the speech was, narrative writing by using humour element to enhance writing skills and factual writing by focusing on imaginary elements and effectiveness of song to convey messages. In total, five assignments managed to be produced by the learners in this writing course. The learners' composition scripts were important because they provided data on the learners' writing proficiency level and indicated relation with writing self-efficacy. According to Pajares (1995, p.10), "researchers in the field of composition believe that although a timed, in-class writing sample is an imperfect reflection of writing ability, it is the most reliable measure available to measure writing development".

\subsection{Pilot study}

A pilot study was carried out on 30 Universiti Putra Malaysia (UPM) students. An analysis using the reliability test Cronbach's Alpha (a) was conducted to ensure the reliability of the constructs. The reliability of all question items in the questionnaire was at a high level depicting .949. A strong reliability was also reported for each construct in this study that is $.954(\mathrm{PS}), .838(\mathrm{OC}), .808(\mathrm{SF}), .801(\mathrm{PR})$.

\subsection{Data Analysis}

The study required quantitative data analyses. Descriptive statistical analysis was used for the quantitative data.

\subsection{Test score standardization}

After all the WSE scores from learners were tabulated, the raw scores had to be standardized in order to make the comparison of the scores achieved by the group comparable. There were three sets of scores used in this process: the aggregate mean, the standard deviation and the Z-scores. In this study, as using the former two could only allow researcher to compare scores within the normal distribution, the researcher had to use Z-scores, because Z-scores allowed the researcher to compare two scores that are from different distributions with different means and standard deviations.

\section{Result}

The discussion of this paper will centre on the high achiever learners' belief in writing ability. In order to select the high achiever writers, the researcher had to choose learners who obtained band 5 to 6 in Malaysian University English Test (MUET) examination. Apart from that, the learners' achievement were observed where five writing tasks were given to the learners and assessed by two different evaluators to determine their level in writing skills. Overall, 8 students were observed to be consistently scored A ( $80 \%$ and above) in all assignments given and all seven of these students were the only students who achieved Band 5 for MUET and one of them achieved IELTS Band 7. These 8 students' writing selfefficacy were then assessed by looking at five different sources of writing self-efficacy namely General Progress (GPR), Specific Progress (SPR), Physiological States (PS), Observational Comparison (OC) and Social Feedback (SF). Zscores were derived from each self-efficacy component score based on the aggregate mean and the standard deviation of the class. Below are the results of writing self-efficacy of the high achiever group: 
Table 2. WSE scores achieved by high achievers

\begin{tabular}{|c|c|c|c|c|c|c|c|c|c|c|}
\hline \multirow{3}{*}{$\begin{array}{l}\text { Subject } \\
\text { ID }\end{array}$} & \multicolumn{10}{|c|}{ SELF-EFFICACY SOURCES } \\
\hline & \multicolumn{2}{|c|}{ GPR } & \multicolumn{2}{|c|}{ SPR } & \multicolumn{2}{|c|}{ PS } & \multicolumn{2}{|c|}{ OC } & \multicolumn{2}{|c|}{ SF } \\
\hline & score & z-score & score & z-score & score & z-score & score & z-score & score & z-score \\
\hline 1 & 32 & +0.041 & 26 & -0.46 & 24 & +0.064 & 31 & +0.45 & 24 & -0.33 \\
\hline 2 & 28 & -0.87 & 22 & -1.58 & 17 & -1.57 & 29 & +0.49 & 23 & -0.58 \\
\hline 3 & 33 & +0.27 & 27 & -0.19 & 29 & +1.23 & 28 & -0.15 & 25 & -0.083 \\
\hline 4 & 39 & +1.63 & 29 & +0.37 & 27 & +0.996 & 31 & +0.45 & 27 & +0.42 \\
\hline 5 & 35 & +0.72 & 30 & +0.65 & 30 & +1.46 & 30 & +0.25 & 29 & +0.92 \\
\hline 6 & 33 & +0.27 & 24 & -1.02 & 25 & +0.3 & 29 & +0.049 & 26 & +0.17 \\
\hline 7 & 38 & +1.41 & 35 & +2.05 & 30 & +0.64 & 41 & +2.47 & 32 & +1.67 \\
\hline 8 & 32 & +0.041 & 33 & +1.49 & 24 & +0.064 & 26 & -0.56 & 26 & -0.33 \\
\hline $\begin{array}{c}\text { Total } \\
\text { z-score }\end{array}$ & & +3.512 & & +1.31 & & +3.178 & & +3.449 & & +1.857 \\
\hline
\end{tabular}

Generally, Table 2 above shows the Z-scores of each individual within the Writing class group. It can be seen that even though there are some upwards and downwards of Z-scores among the individuals within this group, the overall Zscores for each sources of self-efficacy is going upwards reaching 1.3 to 3.5 above the aggregate mean indicating higher than the mean performance. The scores for GPR, PS and OC are actually outside the region between -2 and +2 . These scores perhaps happened due to the special characteristics of groups selected for the discussion of this paper. Where else, the Z-scores for SPR and SF fall between +1 and +2 which indicates a quite good performance or within the range of the highest level of self-efficacy.

However, when comparing the individual scores in detail, it can be seen that highest frequency of negative $z$-value is reported for SPR and SF where half of the subjects obtained -.08 to -.58 for SF and -.10 to -1.6 for SPR. The Z-scores range for both SPR and SF indicate a range between -2 and -1 which means that it is quite bad performance or within the lower range of self-efficacy. Here, in terms of SPR, the low Z-scores indicate that the learners feel that their choices of words, descriptions and order of sentences are not better than before even though they did performed very well in all written assignment and examination. Apart from that, they also do not feel that their writing is clearer and interesting than before. Meanwhile, in terms of SF, the negative and low Z-scores portrays that majority of the high achiever learners, despite their high achievement in writing, they still feel their parents and people around them do not think they can write well.

On the other hand, the highest frequency of positive z-value is in the GPR and PS components with minimum positive $z$-score of +.041 and maximum of +1.63 for GPR. PS indicates a minimum positive $z$-score of +.064 while the maximum value is +1.46 . Altogether five GPR $z$-scores and five PS z-scores are considered as the typical performance of high achiever as the $z$-score within the range of -1 and +1 . Meanwhile two values of $z$-score from GPR and PS respectively falls between +1 and +2 indicates a quite good performance. Frequent positive $z$-scores give the pictures that high achievers feel that overall they can write simple sentences with good grammars and organization. They also feel that they need less teachers' help to write than they used to. While, the frequency of positive value for PS lends a picture that high achiever do actually feel really comfortable while writing and it makes them relax and feel good when they express thought in writing. In sum, psychologically, these high achievers see writing as a mean of enjoyment and in touch with their inner self.

Among the eight high achiever learners, only one learner that is Subject 2 who scored negative z-score for almost all components of self-efficacy (GPR -.87, SPR -1.58, PS -1.57 and SF -.58). This shows that Subject 2 scored very low on GPR, SF, and quite low on SPR and PS. Subject 2 only portrays a high score on OC $(+.49)$ higher than the mean performance indicating that Subject 2 only thinks she or he is better in writing when compared to her/his friends or classmates. On the basis of this information, it can be seen that despite the low perception towards own skills, this high achiever still feels highly better in writing when involved comparison with friends or fellow classmates.

\section{Discussion and Implication}

\subsection{High achiever and social factors perception}

There are several specific characteristics found among these high achievers. Firstly, high achievers in this study undervalue their skills in writing despite the good marks that they obtained in examination and assignments. They feel that their vocabulary, sentence structure and essay structure are not good enough. This phenomenon perhaps can be explained by Wigfield and Karpathian as cited in Sanjay Kumar Nayak and Masroor Jahan (2010) that young children's understanding of competence changes with age, such that with increasing age, self-concepts of ability are likely to be less positive. Thus, it is important for an educator to help learners make their appraisals more accurate by monitoring their self-efficacy. Zimmerman, Bonner and Kovach (1996) as cited in Sara Katz and Gaby Shoshani (2010) recommend a method of monitoring students' self-efficacy by rating their self-appraisals on the graph that their actual test results are plotted. In this way, students immediately see when they have misjudged their own competence and can adjust their standards the next time they appraise their ability to perform a task (Sara Katz and Gaby Shoshani, 2010). 
Apart from that, these high achievers also have different perception towards people around them. Based on the scores, they obviously feel that they haven't meet the expectation of the adults whereby they think adults such as their parents and teachers are not perceiving them as good writers yet. On the other side of the coin, this may perhaps in turn becomes the inner motivation for these high achievers to constantly improve their writing and not just satisfy with the average achievement. This is perhaps consistent with Shashi Kala Singh (2013) analysis on the high and low achiever college learners' characteristics. He found out that high achievers actually have high anxiety and high adjustment in different situation. This is actually a good thing as it provides the motivation learners require to exert effort completing assigned schoolwork and preparing to take examination (Shashi Kala Singh, 2013)

Despite, the negative perception that they have regarding adults' impression on their performance, majority of the high achievers in this study indicate high self-efficacy in terms of social assistance. Firstly, these high achievers do not need teacher's assistance to improve further. This is perhaps an indication that high achievers find themselves equally competent and independent to succeed the proposed tasks and are also equally confident in their responses. This finding is also consistent with Chungui Qiao and Helen Mc Naught (2007) reports on the high achievers of high school learners in New Zealand whom found that high achievers need less help from their teachers in comparison to the lower achiever groups. Besides finding teacher's assistance as less important, these high achievers also believe that they are more capable and can perform well than their peers. This is different when they compare to the adult's perception towards them. Consequently, it can be concluded that the high achievers still appreciate their cognitive abilities where they think they can perform well than their fellow classmates.

\section{Conclusion}

Despite the specific findings of the high achievers' writing self-efficacy, it is worthy of notice to emphasize that the findings of this study should be interpreted by taking into account the limitation that is the specific context of this study. This is because efficacy beliefs are context-specific and this study was only been conducted in a public university in Malaysia and the discussion only centred on a particular group of learners. Thus, this imposes a particular setting and characteristics to the study. It may not be generalized to other population.

Nevertheless, the present study can be a step toward understanding high achievers' beliefs about their writing competence and their actual performance in academic contexts. Further research is needed to address how it is that writing beliefs impact the learning the writing skill and how far high achievers' writing self-efficacy are consistent with their actual performance. Moreover, further research is needed to investigate a bigger context where generalization can be applied to other population.

\section{Acknowledgements}

The author wish to thank Dr Roslina Abu Bakar for helping with the technical set up throughout data collection period. Thanks are also due to Assoc. Prof. Dr. Shamala a/p Paramasivam for all her support for this research.

\section{References}

Artino, Anthony, R.J. (2006). Self-efficacy beliefs from educational theory to instructional Practice. [Online] Available: http://www.eric.ed.gov/ERICWEBPORTAL

Bandura, A. (1977). Social learning theory. New Jersey: Prentice Hall.

Bandura, A. (1997). Self-efficacy: The exercise of control. New York: W.H. Freeman \& Company.

Bottomley, D., Henk, W., \& Melnick, S. (1998). Assessing children's views about as writers using the writer self perception scale. The Reading Teacher, 51(4), pp.286-291.

Chungui Qiao and Helen Mc Naught (2007). Evaluation of Project K. Centre for Social Research and Evaluation, pp.126.

Deborah E. Burns , Scott E. Johnson \& Robert K. Gable (1998) Can we generalize about the learningstyle characteristics of high academic achievers?, Roeper Review, 20(4), pp.276-281.

Katz, S. \&Shoshani, G. (2010). Self-efficacy appraisal and performance of low and high TEFL college achievers: A mixed method study. Shaanan College Annual, 15, pp.E29-E21.

Klassen, R. (2002). Writing in early adolescence: A review of the role of self-efficacy beliefs. Educational Psychology Review 14: 173-203.

Lawrence, J., Ashford, K. \& Dent, P. (2006) Gender differences in coping strategies of undergraduate students and their impact on self-esteem and attainment Active Learning in Higher Education, 7(3), pp.273-281

Linnenbrink, E.A. \& Pintrich, P.R. (2003). The role of self-efficacy beliefs in learner engagement and learning in the classroom. Reading and Writing Quarterly, 19, pp.119-137.

Mok Soon Sang (2008). Educational pyschology \& pedagogy: Learner and learning environment. Selangor: Penerbitan Multimedia Sdn. Bhd.

Pajares, F \& Valiante. (2008). Self-efficacy beliefs and motivation in writing development. In Macarthur, C.A, Graham, S., Fitzgerald, J. (ed.). Handbook of writing research, pp158-170. New York: Guilford Press. 
Pajares, F. (1996). Self-efficacy in Academic Settings. Review of Educational Research, 66, pp.543-578.

Pajares, F. (2002a). Electronic sources: Self-efficacy beliefs in academic contexts: An outline. [Online] Available: http://des.emory.edu/mfp/efftalk.html

Pajares, F. (2002b). Gender and perceived self-efficacy in self-regulated learning. Theory into Practice, 41, pp.116-125.

Pastorelli, C., Caprara, G.V., Barbaranelli, C.,Rola, J., Rozsa, S. \& Bandura, A. (2001). The structure of children's perceived self-efficacy: A cross-national study. European Journal of Psychological Assessment, 17, pp.87-97.

Sanjay Kumar Nayak and Masroor Jahan (2010). Cross-sectional analysis of psychological aspects of adolescent underachievers Industrial Psychiatry Journal. 19(2), pp.105-110.

Scholz, U., Gutierrez-Dona, B., Sud, S. \& Schwarzer, R. (2002). Is general self-efficacy a universal construct? Psychometric findings from 25 countries. European Journal of Psychological Assessment,18, pp.242-251.

Schunk, D.H. (2003). Self-efficacy for reading and writing: Influence of modelling, goal setting, and self-evaluation. Reading and Writing Quarterly 19, pp.169-172.

Shashi Kala Singh (2013) Anxiety and Adjustment Pattern of High and Low Academic Achievers. Global Research Analysis (GRA) Research Paper, pp.25-26.

Strauser, D. (1995). Applications of self-efficacy theory in rehabilitation counselling. Journal of Rehabilitation,61(2), pp.7-11. 